\title{
High Pressure Property Relationship Chart of Crude Oil and Its Application in Offshore Oil Fields Reserve Estimation
}

\author{
Li Hua ${ }^{1,2}$, Peng Xiaodong ${ }^{1}$, Tong Luyi ${ }^{1}$, Li Hao ${ }^{1}$, Lu Yan ${ }^{1}$ \\ ${ }^{1}$ CNOOC Ltd._Z Zhanjiang, Zhanjiang, Guangdong, China \\ ${ }^{2}$ Reservoir Engineering, CNOOC Ltd._Zhanjiang, Zhanjiang, Guangdong, China
}

\section{Email address:}

Lihua8@cnooc.com.cn (Li Hua), pengxd@cnooc.com.cn (Peng Xiaodong), tongly@cnooc.com.cn (Tong Luyi), Lihao2@cnooc.com.cn (Li Hao), luyan15@cnooc.com.cn (Lu Yan)

\section{To cite this article:}

Li Hua, Peng Xiaodong, Tong Luyi, Li Hao, Lu Yan. High Pressure Property Relationship Chart of Crude Oil and Its Application in Offshore Oil Fields Reserve Estimation. International Journal of Oil, Gas and Coal Engineering. Vol. 4, No. 1, 2016, pp. 1-8.

doi: 10.11648/j.ogce.20160401.11

\begin{abstract}
Formation oil high pressure property parameters are essential to the reserve estimation and development plan compilation of oil fields. Due to the high cost and safety concerns of offshore oilfields, only a small amount of PVT samples can be obtained from exploration wells and appraisal wells, in some cases, there will be no samples or samples cannot present the actual conditions like degas. To solve the difficulty of obtaining high pressure property parameters during the appraisal stage of offshore oilfields, this article raised a new analogy method: high pressure property relationship chart. The existing high pressure property data can be regressed to a regional chart, and the chart can be utilized to predict high pressure property parameters. This method can realized the idea that formation oil high pressure property parameters can be predicted by surface oil samples or MDT density. Exploration practices in Beibuwan Basin show that this method can predict high pressure property parameters of formation oil well.
\end{abstract}

Keywords: PVT, Sampling, Regional Chart, Offshore Oilfield, Beibuwan Basin

\section{Introduction}

Formation oil high pressure property parameters are essential to the reserve estimation and development plan compilation of oil fields, and these parameters are usually got from PVT samples analysis [1, 2]. Major methods for offshore exploration wells and appraisal wells PVT sampling are: DST [3], MDT [4-7], Focusing Sampling [8, 9], and Formation Test While Drilling $[10,11]$, etc., and the first two methods are the most commonly used ones [2]. Offshore oilfields sampling possesses specialties when compared to that of the onshore fields: for one thing, the amount of exploration and appraisal wells are quite small and the PVT sampling expenditure is rather high, thus, the quantity of obtained PVT samples are relatively small; furthermore, as to small-scaled reservoirs, productivity test or PVT sampling will not even be carried out; for another, complex situations often occur during the offshore sampling, such as degas, low-productivity, etc., and these situations will disable PVT samples and cannot truly present the formation fluid properties.

In terms of the specialties, in addition to drawing lessons and trying to get representative fluid samples, another effective method for high pressure property parameters correction and prediction should be acquired. Currently, the commonly used methods are parameters analogy of adjacent blocks [12] and empirical method [13, 17]. However, as to blocks that are far away from each other, it will have a certain degree of errors by analogy method, especially for complex faulted reservoir in Beibuwan Basin [12]; at the same time, empirical method will have errors as well. Previous studies show that there are certain rules of crude oil in the same basin [12, 19-23], and based on this idea, this article raised a new analogy method: crude oil high pressure property relationship chart. Through 30 years of exploration and development in Beibuwan Basin, abundant PVT samples and high pressure property data have been acquired. On the foundation of these materials, crude oil high pressure property relationship chart can be obtained, and the chart can be applied to correct abnormal PVT samples and predict PVT parameters of reservoirs that have no samples or are going to carry out the sampling procedures. In conclusion, this method will solve the difficulty of PVT parameters acquisition. 


\section{The Establishment of High Pressure Property Relationship Chart}

Till the end of 2013, 178 PVT samples in Nanhai West have been obtained and 102 samples are from Beibuwan Basin, particularly, 12 samples are from Jiaowei Formation, 2 samples are from W2 Member, 31 samples are from W3 Member, 21 samples are from L1 Member, 6 samples are from L2 Member, 13 samples are from L3 Member. Through result regression analysis of formation oil high pressure property experiment in 102 samples in Beibuwan Basin, 8 regional high pressure property relationship charts are gained, and the regression coefficients are favorable. Thereinto, linear relationship of formation oil density and surface oil density, volume coefficient and gas/oil ratio matches well; exponential relationship of formation oil viscosity and formation oil density, saturation pressure and formation oil density, solution gas/oil ration and formation oil density matches well; trinomial relationship of volume coefficient and formation oil density matches well; power function relationship of formation oil viscosity and gas/oil ration matches well.

What's more:(1) low saturated reservoirs and high saturated reservoirs present two different rules in the formation oil density surface oil density chart, thus, samples are respectively regressed in terms of low and high formation-saturation pressure differential; (2) conventional light oil and heavy oil reservoirs show obvious differences in the formation oil viscosity formation oil density chart and the formation oil viscosity original GOR chart, thus, samples are respectively regressed in terms of light and heavy oil reservoirs.

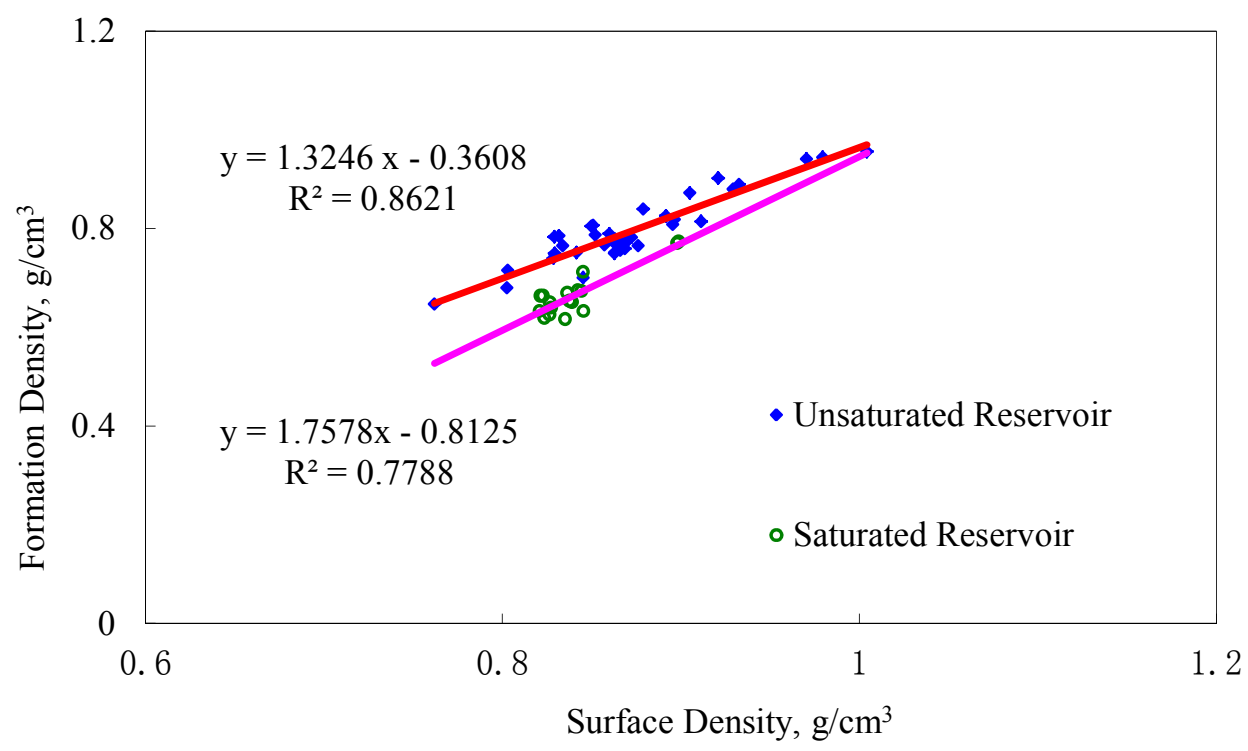

Fig. 1. Formation and Surface Oil Density Relationship Chart in Beibuwan Basin.

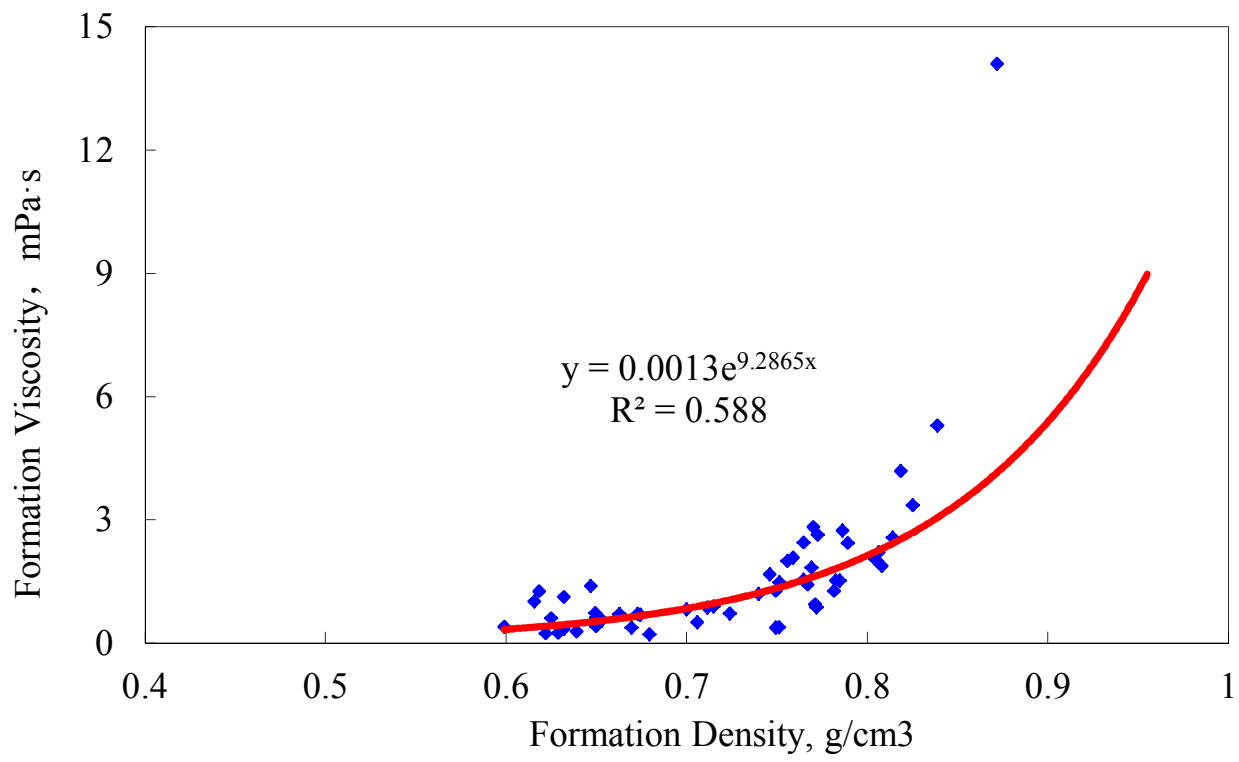

(a) Conventional Light Oil Reservoir (Formation Oil Density is less than $0.8 \mathrm{~g} / \mathrm{cm} 3$ ) 


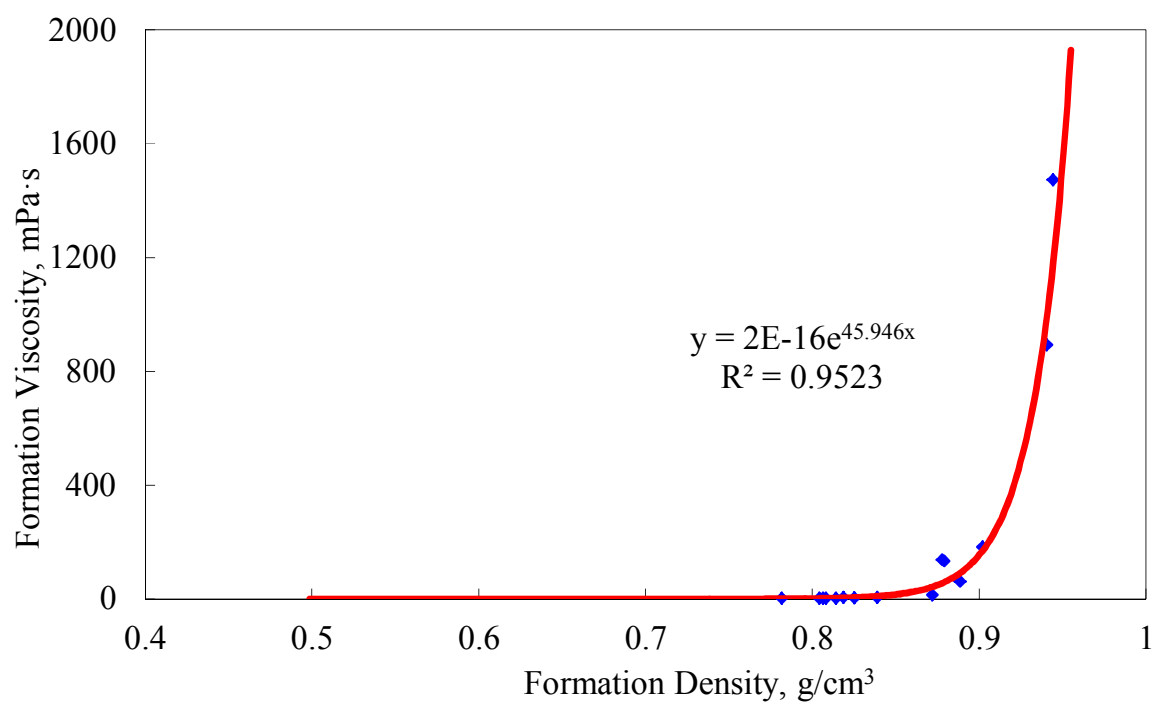

(b) Heavy Oil Reservoir(Formation Oil Density is higher than $0.8 \mathrm{~g} / \mathrm{cm} 3$ )

Fig. 2. Formation Oil Viscosity and Density Relationship Chart in Beibuwan Basin.

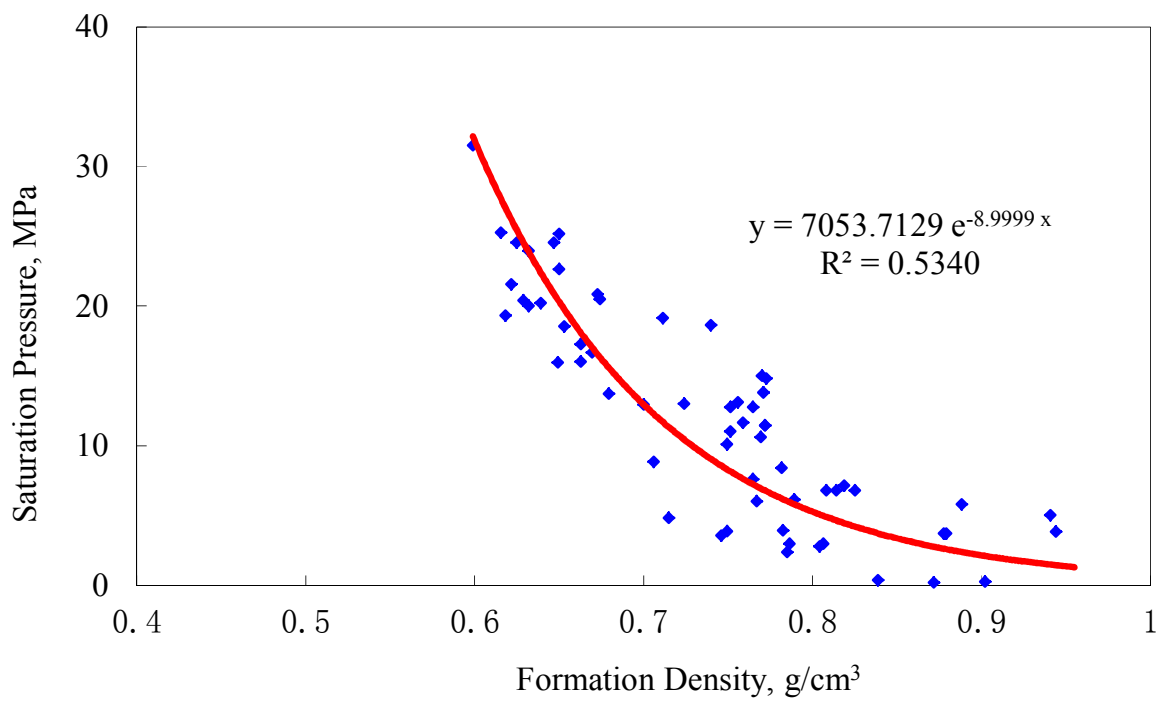

Fig. 3. Saturation Pressure and Formation Oil Density Relationship Chart in Beibuwan Basin.

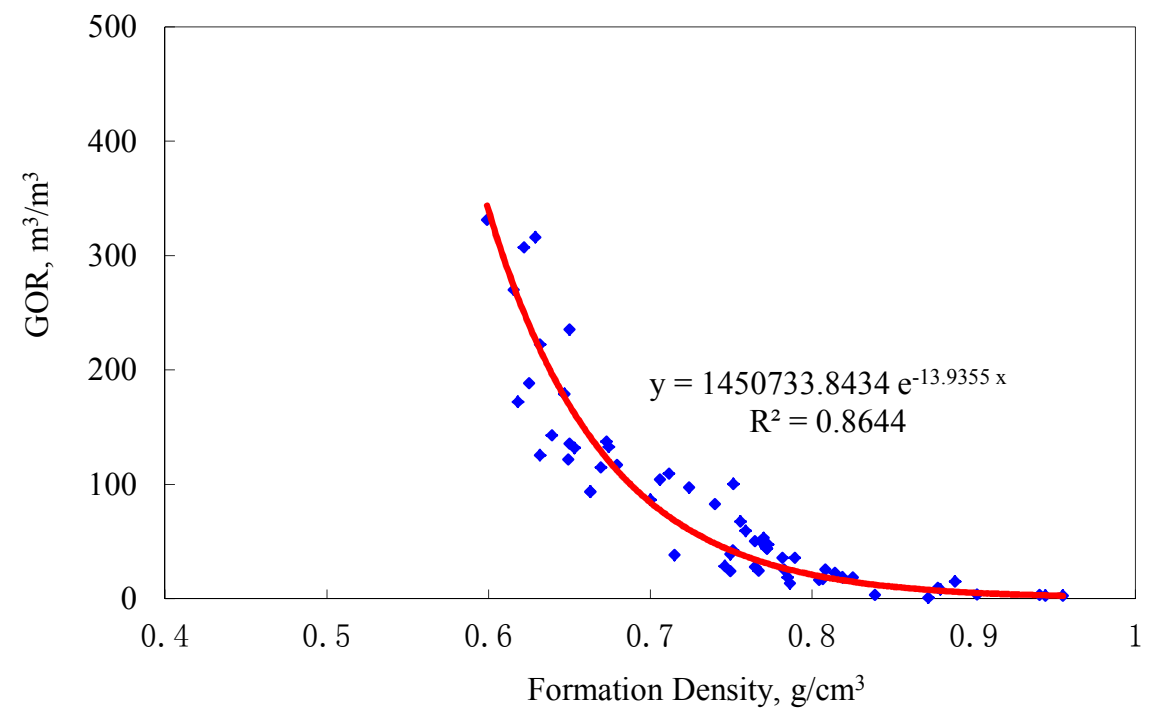

Fig. 4. GOR and Formation Oil Density Relationship Chart in Beibuwan Basin. 
4 Li Hua et al.: High Pressure Property Relationship Chart of Crude Oil and Its Application in Offshore Oil Fields Reserve Estimation

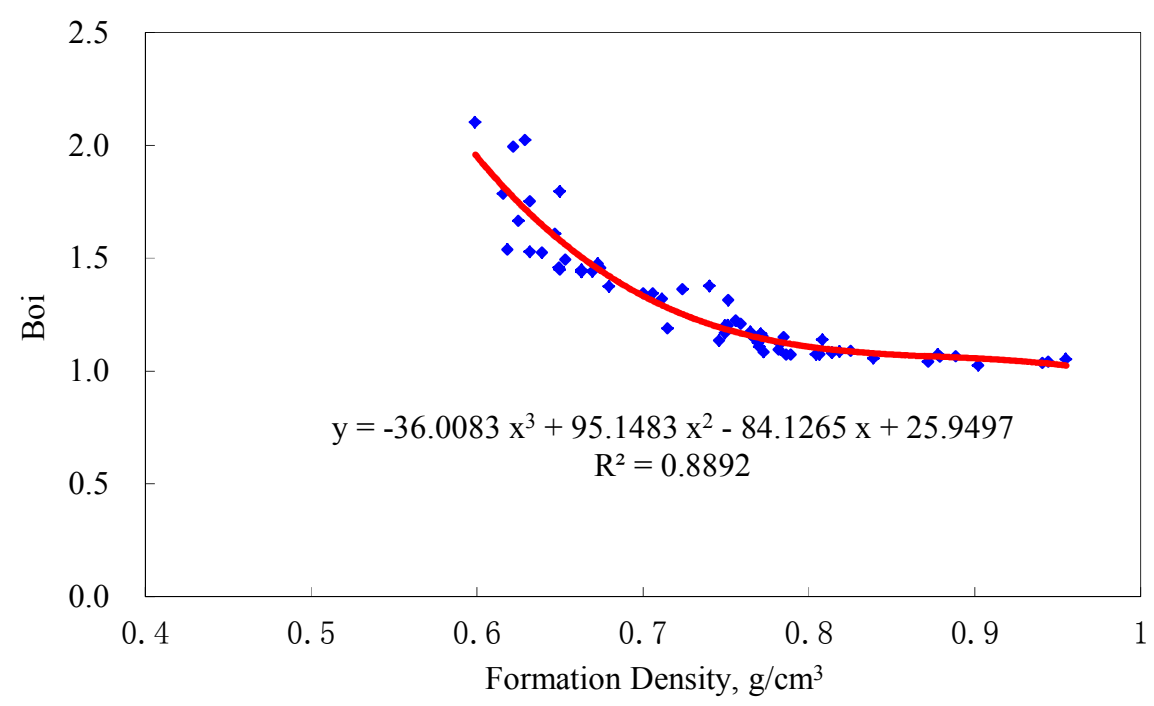

Fig. 5. Boi and Surface Oil Denstiy Relationship Chart in Beibuwan Basin.

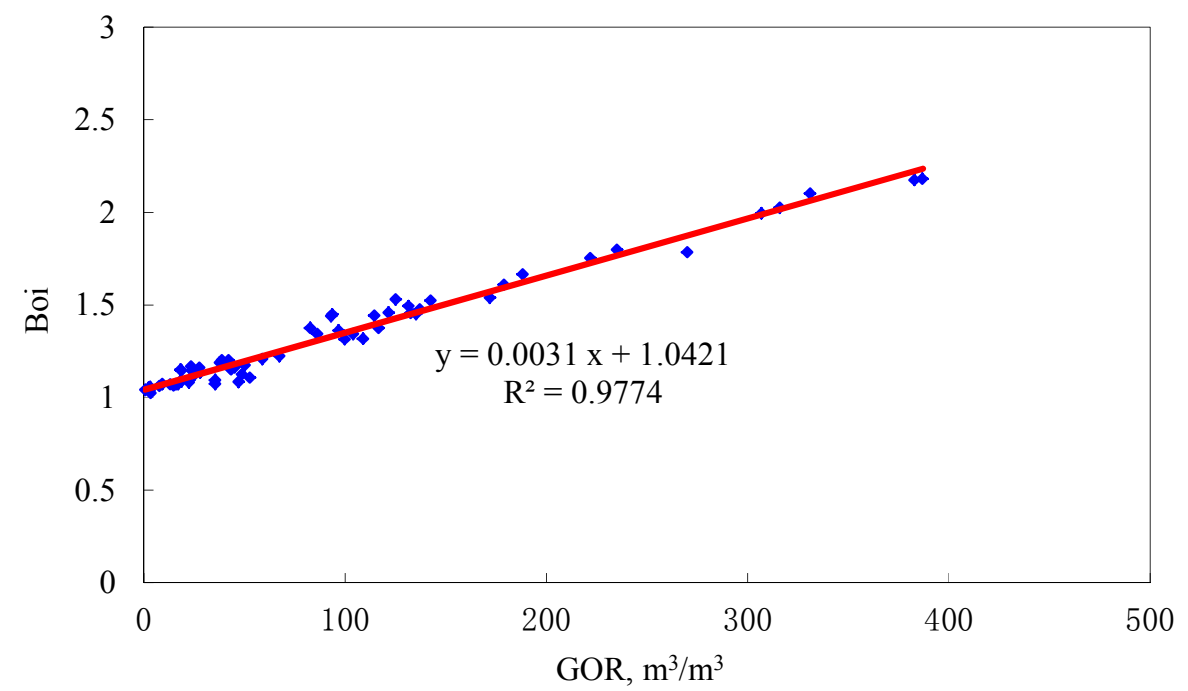

Fig. 6. Boi and GOR Relationship Chart in Beibuwan Basin.

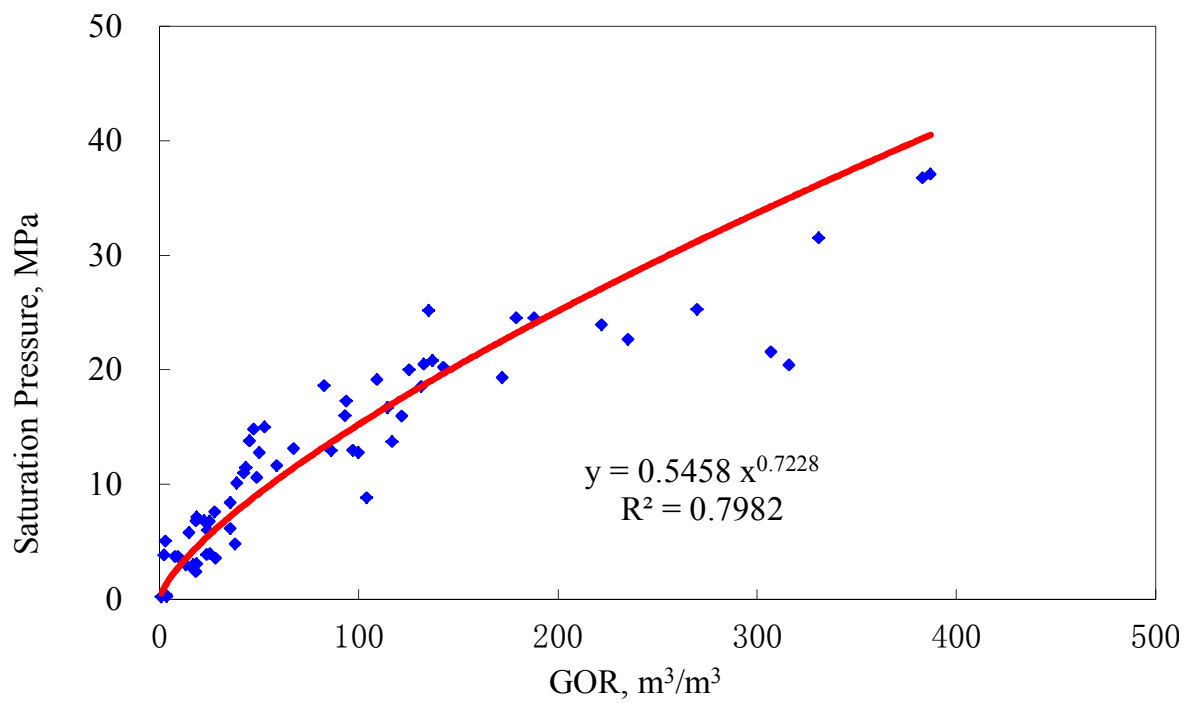

Fig. 7. Boi and GOR Relationship Chart in Beibuwan Basin. 


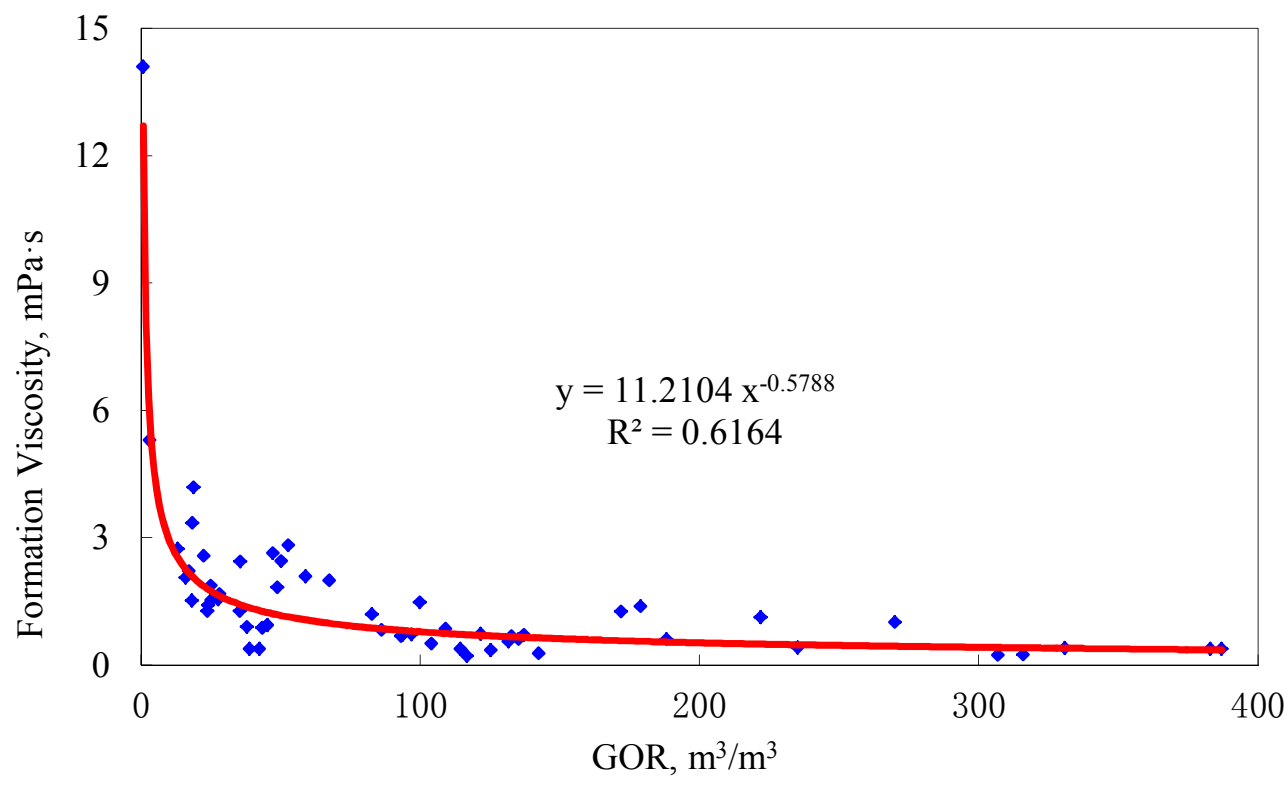

(a) Conventional Light Oil Reservoir(GOR is higher than $\left.15 \mathrm{~m}^{3} / \mathrm{m}^{3}\right)$

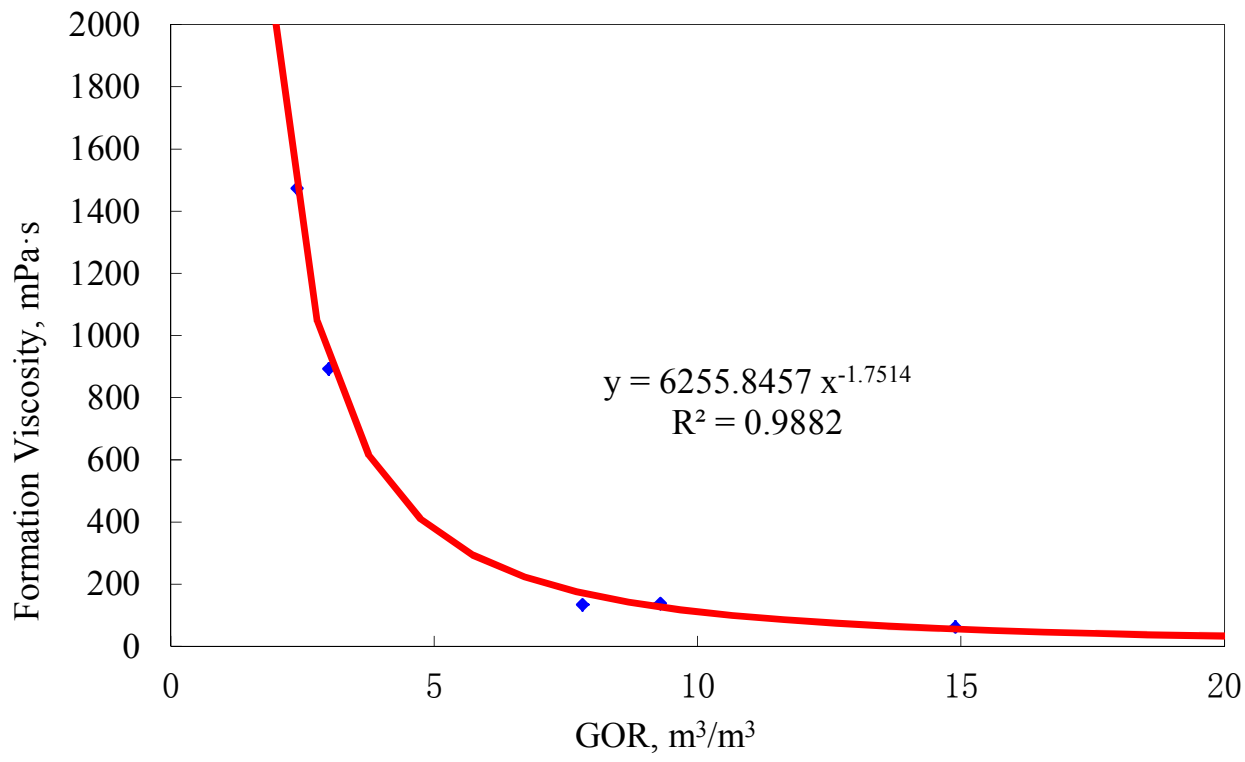

(b) Heavy Oil Reservoir(GOR is less than $15 \mathrm{~m}^{3} / \mathrm{m}^{3}$ )

Fig. 8. Formation Oil Viscousity and GOR Relationship Chart in Beibuwan Basin.

\section{The Application of High Pressure Property Relationship Chart}

\subsection{Prediction Procedure of High Pressure Property Relationship Chart}

PVT sampling of offshore exploration and appraisal wells can be typically classified as DST Test and MDT Test. DST test can obtain downhole samples as well as separator samples, while MDT test can only get downhole samples. The key to downhole sampling is the guarantee of the pressure higher than saturation pressure, so that the samples will present the actual formation conditions [2]. As to unsaturated reservoirs, analysis results from downhole sample are normally utilized, while as to saturated reservoirs, analysis results will be from the recombination and re-mixture of surface samples contained in the separator [18].

Therefore, saturation pressure plays an important guiding role in the sampling method and sampling procedure. As to appraising oil-bearing structures, the saturation pressure of samples can only be got through prediction. Currently, the commonly used methods are empirical method and analogy method. However, practices show that empirical method tends to have great errors while analogy method is inapplicable in blocks that are far away. In order to solve the problem, this article raised the method that formation oil high pressure property parameters can be predicted by surface oil samples or MDT density. Detailed procedures can be referred to Fig. 9. 


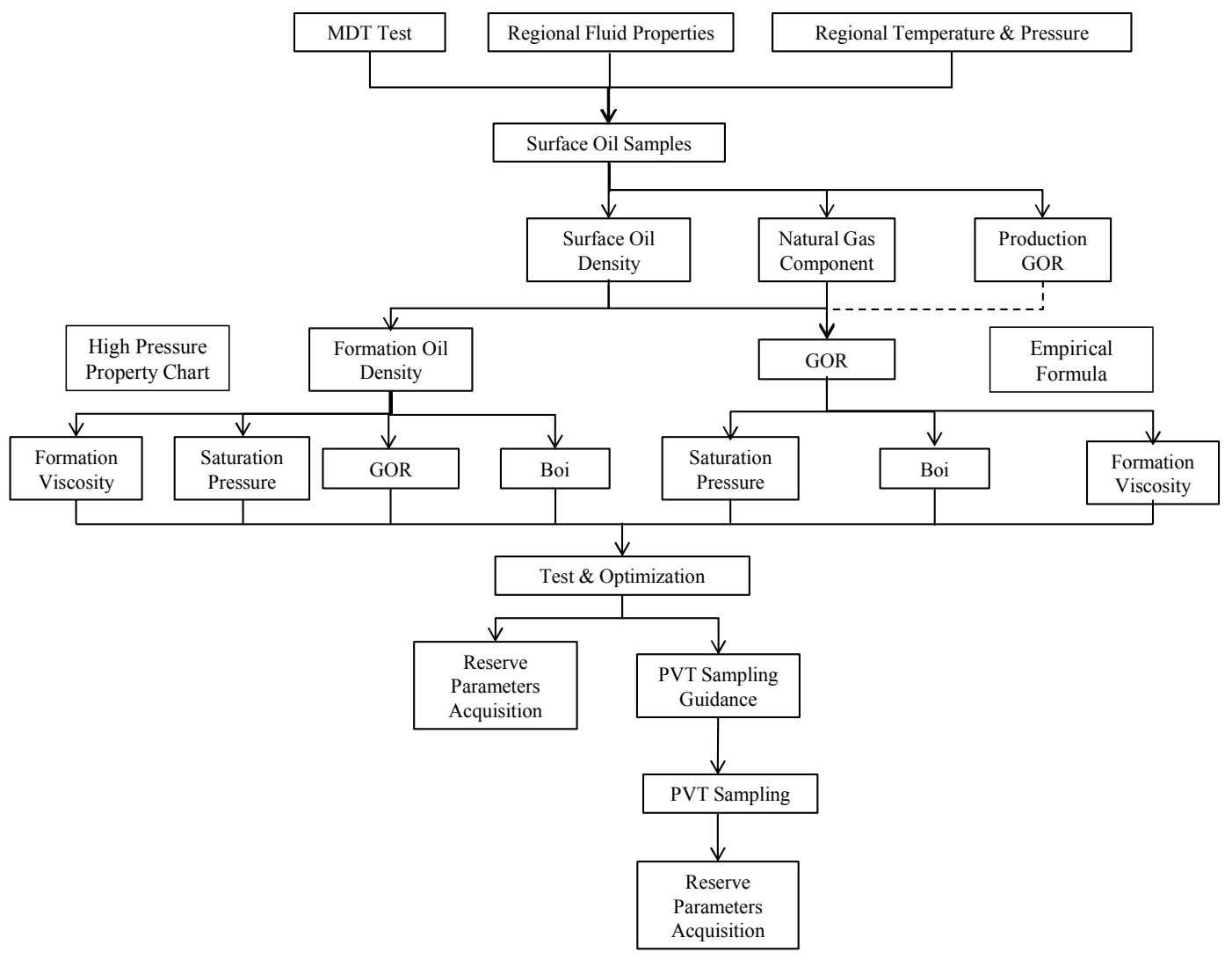

Fig. 9. Oil High Pressure Property Parameters Prediction Procedure Chart.

\subsection{Examples}

Take $\mathrm{L}_{1}$ II oil group of an oil filed for example. Well S1 was drilled in the first place, no DST test was carried out in $\mathrm{L}_{1}$ II oil group, and 3 surface oil samples through MDT test were obtained. Particularly, 2 samples were released at the site, and the volume ratio between gas samples and oil samples is 76 ; the remaining 1 sample was taken back to the laboratory to carry out surface oil property analysis. According to the experimental results, the surface oil density is $0.839 \mathrm{~g} / \mathrm{cm}^{3}$, and the relative density of solution gas is 0.833 . Meanwhile, as the quality of MDT test is favorable, formation oil density which is derived from the pressure equation based on pressure test data regression is $0.765 \mathrm{~g} / \mathrm{cm}^{3}$ (Fig. 10), and mid-depth pressure of the reservoir is $28.514 \mathrm{MPa}$; mid-depth temperature derived from regional temperature regression equation is $125.58^{\circ} \mathrm{C}$ (Table 1$)$.

Table 1. MDT Test and Sampling Analysis Results Table of Well S1.

\begin{tabular}{|c|c|c|c|c|c|c|c|}
\hline \multicolumn{2}{|l|}{ Sample } & \multirow{2}{*}{$\rho_{o \text { Surface }} \mathbf{g} / \mathrm{cm}^{3}$} & \multirow{2}{*}{$\begin{array}{l}R_{\mathrm{P}} \mathrm{m}^{3} / \mathrm{m}^{3} \\
\text { (Field Analysis) }\end{array}$} & \multirow{2}{*}{$\gamma_{g s}$} & \multirow{2}{*}{$\begin{array}{l}\rho_{\mathrm{o} \text { Formation }} \mathrm{g} / \mathrm{cm}^{3} \\
\text { (MDT Test) }\end{array}$} & \multirow{2}{*}{ Р Мpa } & \multirow{2}{*}{$\mathbf{T}^{\circ} \mathbf{C}$} \\
\hline Wellname & Layer & & & & & & \\
\hline S-1 & $\mathrm{L}_{1} \mathrm{II}$ & 0.839 & 76 & 0.833 & 0.765 & 28.524 & 125.58 \\
\hline
\end{tabular}

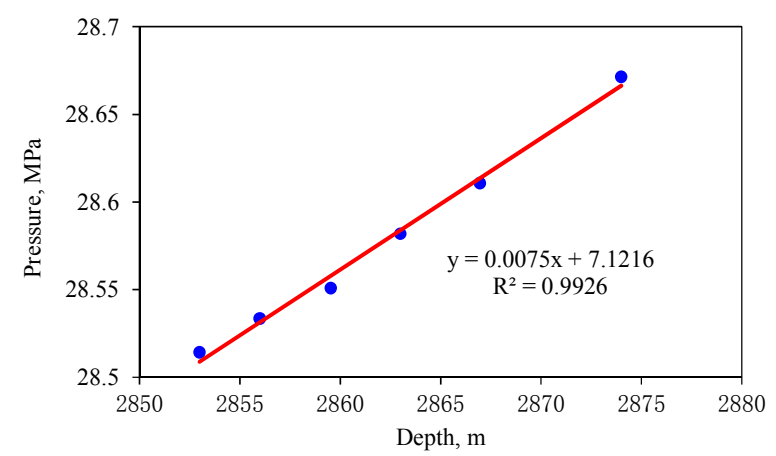

Fig. 10. MDT Test Regression Curve of $L_{1} I I$.
As there are no available PVT samples, to acquire reserve estimation parameters, both empirical method and chart method are adopted. According to the results from empirical equation method (Table 2): GOR is $191 \mathrm{~m}^{3} / \mathrm{m}^{3} \sim 195 \mathrm{~m}^{3} / \mathrm{m}^{3}$, and it is a strike contrast with the filed release $76 \mathrm{~m}^{3} / \mathrm{m}^{3}$.

When the chart method is applied, the formation oil density is derived from the surface oil density, and the result is $0.751 \mathrm{~g} / \mathrm{cm}^{3}$ by utilizing low-saturated reservoir model, which is close to the MDT test regressed $0.765 \mathrm{~g} / \mathrm{cm}^{3}$; the GOR is $41 \mathrm{~m}^{3} / \mathrm{m}^{3}$ by utilizing low-saturated reservoir model, which is close to the field release $76 \mathrm{~m}^{3} / \mathrm{m}^{3}$. Therefore, formation oil density and GOR results come from the low-saturated reservoir model prediction results, further, the results will be applied to 
predict Boi, saturated-pressure and formation oil viscosity, the general results are as follows (Table 3).

Table 2. High Pressure Physical Property Results Calculated by Empirical Equation.

\begin{tabular}{llllll}
\hline Empirical Equation & $\mathbf{R}_{\mathbf{S}} \mathbf{m}^{\mathbf{3}} / \mathbf{m}^{\mathbf{3}}$ & $\mathbf{P}_{\mathbf{b}} \mathbf{M P a}$ & $\mathbf{B o}$ & $\boldsymbol{\mu}_{\mathbf{0} \text { Formation }} \mathbf{C P}$ & Note \\
\hline standing & 195 & 28.364 & 1.712 & & \\
lasater & & 26.633 & & & \\
Glaso & 191 & 29.119 & 1.002 & 0.503 & $\mathrm{RS}$ is adopted $195 \mathrm{~m}^{3} / \mathrm{m}^{3}$ when calculating \\
VB & & 30.702 & & & $\mathrm{P}_{\mathrm{b}} / \mathrm{B}_{\mathrm{o}} / \mu_{\mathrm{oF}}$ cormation $; \mathrm{P}_{\mathrm{b}}$ is adopted $28.364 \mathrm{MPa}$ when \\
Daqing & & 42.908 & & \\
MD & & 20.572 & & \\
Marhoun & & 3931.494 & 2.136 & & \\
PF & & -589.654 & 1.188 & 0.502 & \\
Beal & & & & & \\
\hline
\end{tabular}

Table 3. High Pressure Physical Property Results Calculated by Chart Method.

\begin{tabular}{|c|c|c|c|c|c|c|c|c|c|c|c|c|}
\hline \multicolumn{2}{|c|}{ Samples } & \multirow{2}{*}{$\begin{array}{l}\rho_{\text {oSurface }} \\
\mathrm{g} / \mathrm{cm}^{3}\end{array}$} & \multicolumn{2}{|c|}{$\rho_{\text {oformation }} \mathbf{g} / \mathrm{cm}^{3}$} & \multicolumn{2}{|l|}{$\mathbf{R}_{\mathrm{S}} \mathbf{m}^{3} / \mathbf{m}^{3}$} & \multicolumn{2}{|l|}{ Bo } & \multicolumn{2}{|l|}{$\mathbf{P}_{\mathrm{b}} \mathbf{M P a}$} & \multicolumn{2}{|c|}{$\mu_{\text {OSurface }} \mathrm{CP}$} \\
\hline $\begin{array}{l}\text { Well } \\
\text { name }\end{array}$ & Layer & & $\begin{array}{l}\text { Low-Sa } \\
\text { turated }\end{array}$ & $\begin{array}{l}\text { High-Sa } \\
\text { turated }\end{array}$ & $\begin{array}{l}\text { Low-Sa } \\
\text { turated }\end{array}$ & $\begin{array}{l}\text { High-Sa } \\
\text { turated }\end{array}$ & $\rho_{\text {oSurface }}$ & $\mathbf{R S}$ & $\rho_{0 \text { Surface }}$ & RS & $\rho_{0 \text { Surface }}$ & RS \\
\hline S-1 & $\mathrm{L}_{1} \mathrm{II}$ & 0.839 & 0.751 & 0.663 & 41 & 142 & 1.183 & 1.171 & 8.200 & 8.059 & 1.387 & 1.298 \\
\hline
\end{tabular}

Note: $\rho_{\text {oformation, }}$ RS is adopted low-saturated model.

To further verify the oil-bearing area of the oilfield, another well S2 was drilled and PVT sampling was carried out. Before the sampling, the saturation pressure was predicted by the chart method: the saturation pressure is $8 \mathrm{MPa}$ based on low-saturated reservoir model, while the saturation pressure is $18 \mathrm{MPa}$ based on high-saturated reservoir model. During the sampling procedure, the pressure maintained as $25.396 \mathrm{MPa}$, which was higher than $18 \mathrm{MPa}$. Compared to the laboratory analysis of the PVT experiment (Table 4): (1) Sampling pressure is higher than the saturation pressure, so that the sample can present the actual formation condition; (2) the experiment results are close to the results calculated by chart method of Well S1, while they are far from the results calculated by empirical equation, which shows the reliability of chart method.

Table 4. High Pressure Physical Property Analysis Table of Well S2.

\begin{tabular}{|c|c|c|c|c|c|c|c|}
\hline \multicolumn{2}{|l|}{ Sample } & \multirow{2}{*}{$\rho_{\text {o Surface }} \mathbf{g} / \mathbf{c m}^{3}$} & \multirow{2}{*}{$\rho_{0 \text { Formation }} \mathrm{g} / \mathrm{cm}^{3}$} & \multirow{2}{*}{$\mathbf{R}_{\mathrm{s}} \mathbf{m}^{3} / \mathbf{m}^{3}$} & \multirow{2}{*}{ Вo } & \multirow{2}{*}{$\mathbf{P}_{\mathrm{b}} \mathbf{M P a}$} & \multirow{2}{*}{$\mu_{0 \text { Formation }} \mathrm{CP}$} \\
\hline Wellname & Layer & & & & & & \\
\hline S-2 & $\mathrm{L}_{1} \mathrm{II}$ & 0.844 & 0.722 & 63 & 1.276 & 8.950 & 1.35 \\
\hline
\end{tabular}

\section{Conclusions}

There is good regional relationship among high pressure physical properties in Beibuwan Basin. Saturation pressure predicted by high pressure property relationship chart can guide the sampling procedure in exploration and appraisal wells, so that well sampling failure can be avoided. On the other hand, it can help calculating high pressure physical property parameters to oil field without sampling or failure sampling. To ensure maximum reliability of the results, suggest comparing chart method result and other relative methods such as empirical method, and testing conformance.

\section{Nomenclature}

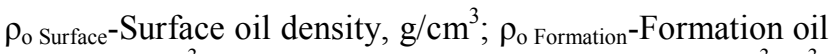
density, $\mathrm{g} / \mathrm{cm}^{3} ; \mathrm{R}_{\mathrm{P}}$-Producing gas/oil ration, $\mathrm{m}^{3} / \mathrm{m}^{3}$; $\mathrm{R}_{\mathrm{S}}$-Solution gas/oil ration, $\mathrm{m}^{3} / \mathrm{m}^{3} ; \gamma_{\mathrm{gs}}$-Relative density of solution gas, dimensionless; P-Formation pressure, MPa; T-formation temperature, ${ }^{\circ} \mathrm{C} ; \mathrm{P}_{\mathrm{b}}$-Saturation pressure, $\mathrm{MPa}$; $\mathrm{B}_{\mathrm{o}}$-Oil volume coefficient, dimensionless; $\mathrm{B}_{\mathrm{oi}}-\mathrm{Oil}$ volume coefficient in formation pressure, dimensionless; $\mu_{\mathrm{o}}$ Formation-Formation oil viscosity, $\mathrm{mPa} \cdot \mathrm{s}$;

\section{References}

[1] Zhao Wenzhi, Hu Suyun, Bi Haibin. Variations in fluid flow parameters of reservoirs and their implications in reserves estimation [J]. China Offshore Oil and Gas, 2006, 6 (18): 390-393.

[2] Jiang Liping, Gao Dewei, Lao Yechun, et al. A technical solution for PVT sampling under complex reservoir conditions in the western South China Sea [J]. China Offshore Oil and Gas, 2012, 1 (24): 36-40.

[3] Li Maohua, Luo Chengyao, Wu Jun. RD Sampling Apparatus and Its Application [J]. Well Testing, 2003, 12 (4): 67-68.

[4] Zhang Hong, Zhao Yu long, Jiang Zhuangde. Sampling techniques in the wireline formation tester [J]. Journal of Xi'an Shiyou University (Natural Science Edition), 2005, 20 (6): 63-67.

[5] Zhang Guodong, Shi Rongfu, Wang Dan, et al. An innovative and effective way for cable sampling in ultra-tight reservoirs in Xihu sag, East China Sea [J]. China Offshore Oil and Gas, 2015, 27 (2): 39-43.

[6] He Bingzhen, Liu Hui, Cai Maojia. Mini-DST formation test technology and its application in Well CH $6[\mathrm{~J}]$. Mud Logging Engineering, 2010, 3 (21): 71-77. 
[7] Yangy Xingqin, Wang Shunan, Zhou Zihao. Progresses in Formation Testing and Subsurface Fluid Sampling \& Analysis Technology [J]. Well Logging Technology, 2012, 6 (36): 551-558.

[8] MA Jianguo, MA Kaide, NI Jun, et al. Focused Sampling of Reservoir Fluids Achieves Undetectable Levels of Contamination [J]. Well Logging Technology, 2008, 4 (32): 375-379.

[9] Ridvan Akkurt, Martin Bowcock, John Davies. A New Method of Subsurface Fluid Sampling. Schlumberger Company «New Technology in Oil Field» 2006/2007 Winter Publication: 4-19.

[10] Ren Guofu, Ma Jianguo. A Technique of Formation Pressure Testing While Drilling and Its Application. Well Logging Technology, 2005, 29 (4): 385-387.

[11] Yang Chuan Chen Ping Ma Tianshou, et al. New Technology of Formation Fluid Sampling While Drilling and Application [J]. China Petroleum Machinery, 2013, 1 (41): 101-104.

[12] Hu Xinzhong, The Application of Well Site Surface Oil Density in Calculating Formation Oil Property Parameters [J]. Inner Mongolia Petrochemical Industry, 2008, 8: 143-146.

[13] Zhu Huashu. PVT Parameters and Phrase Behaviors Prediction Methodologies [D]. Southwest Petroleum University, 2006: 20-68.

[14] Yang Jisheng, Liu Jianyi. Gas Production Technology Fundamentals [M]. Beijing: Petroleum Industry Press, 1992: 23-38.

[15] Zheng Junde, Zhang Yanqiu, Li Guangdan, et al. Change of Sazhong Region's Oil Bubble Point Pressure in the Process of Flooding [J]. Journal of Daqing Petroleum Institute, 1997, 4 (21): $22-25$
[16] Zheng Junde, Sun Zhi, Sun Pinyue. Determination of Oil Saturation Pressure Correlations For Sa, Pu and Gao Reservoirs in Sazhong area of Daqing Oil Field [J]. Petroleum Exploration and Development, 1997, 01 (24): 59-62.,

[17] Zhou Qingjun, Zhang Jiaqing, Ma Huali. The Algorithm and Its Contrast Aimed at Oil PVT Parameters [J]. Well Testing, 2003, $2(12): 31-34$

[18] Li Ruiqi. Surface Oil High Pressure Physical Property Parameters Prediction Method [J]. Oil-Gasfield Surface Engineering, 2009, 9 (28): 81-82.

[19] Zhang Zhongmin, Xiao Ancheng, Pu Xiaoling, et al. Physical Relationships Analysis Between Surface and Formation Oil[J]. Oil-Gasfield Surface Engineering, 2006, 7 (25): 8-9.

[20] Xie Chen, Hai Junjie, Liu Zhengjun, et al. Physical Property Variation of Curde Oil in Beach Area, Liaohe Basin[J]. Petroleum Geology \& Experiment, 2010, 3 (32): 282-284.

[21] Zhou Xingxi. Differentiation Process inside Oil and Gas Fields: Example from the Yaha Oil and Gas Condensate Field in the Tarim Basin [J]. Geological Review, 2003, 5 (49): 507-512.

[22] Li Chuanliang, Zhang Xuelei. An Analysis of Difference of In-Place Oil and Gas Property [J]. Xinjiang Petroleum Geology, 2006, 6 (27): 766-767.

[23] Li Aifen, Wang Shoulong, Lü Jiao, et al. Effect of the Composition of Formation Crude Oil on PVT Data[J]. Xinjiang Petroleum Geology, 2014 (03): 299-302. 